\title{
Optimization of Caving Technology in an Extrathick Seam with Longwall Top Coal Caving Mining
}

\author{
Liu Yang, ${ }^{1,2}$ Lianghui Li, ${ }^{1,2}$ and Weijie Wei $\mathbb{D}^{1,2}$ \\ ${ }^{1}$ School of Energy and Mining Engineering, China University of Mining and Technology-Beijing, Beijing 100083, China \\ ${ }^{2}$ Coal Industry Engineering Research Center of Top-Coal Caving Mining, Beijing 100083, China \\ Correspondence should be addressed to Weijie Wei; wilson1998@foxmail.com
}

Received 4 June 2021; Revised 6 July 2021; Accepted 16 July 2021; Published 4 August 2021

Academic Editor: Xin Cai

Copyright (c) 2021 Liu Yang et al. This is an open access article distributed under the Creative Commons Attribution License, which permits unrestricted use, distribution, and reproduction in any medium, provided the original work is properly cited.

The optimization of top coal caving technology is an efficient method to improve the recovery ratio in longwall top coal caving (LTCC). In extrathick coal seams, the conventional single-opening sequential caving technology (SOSCT) shows the following problems: low recovery ratio, high rock mixed ratio, and poor drawing balance. For these problems, this research verifies the applicability of multiopening caving technology (MOCT) in extrathick coal seams theoretically. However, different drawing sequences have a great effect on the drawing mechanism. Based on the progressive drawing sequence of cluster-group-support, this paper firstly proposes a systematic naming method for the top coal caving technology. Furthermore, an independent cluster-group caving technology (ICGCT) is given, meaning that all supports are divided into several clusters, a cluster is divided into several groups, and clusters extract top coal in positive order while groups are in reverse order in the drawing process. By establishing an experimental model by the discrete element method $\mathrm{PFC}^{2 \mathrm{D}}$, the drawing mechanism is investigated under different caving technologies. The results show that ICGCT significantly improves the recovery ratio of the panel and mainly increases the drawing volume of top coal in the middle and upper end of the panel. The shape of the top coal boundary reflects the drawing efficiency. Due to the effect of drawing sequence in ICGCT, the generation and disappearance processes of coal ridge greatly decrease the residual top coal in the middle of the panel. The drawing body shape has a direct influence on the recovery ratio. Multiple complete drawing bodies exist in ICGCT, and the dispersion coefficient of drawing volume changes periodically in the range of $0.5-1.7$, which is conducive to the management of drawing processes. In addition, discussing ICGCT and the dependent cluster-group caving technology (DCGCT), it is found that the recovery ratio of DCGCT has a slight increase, which enlarges the maximum drawing range of top coal at both panel ends, shortening the total drawing time of the panel. In summary, ICGCT provides a new approach for improving the recovery ratio and drawing balance in LTCC with an extrathick coal seam.

\section{Introduction}

The longwall top coal caving (LTCC) is the main method to extract thick and extrathick coal seams. Figure 1 shows the basic procedure of LTCC. A longwall fully mechanized mining is arranged at the bottom coal seam, where the coal is cut by the shearer, with transporting out of the panel by the front scraper conveyor. Furthermore, the top coal body is broken into loose blocks under the effect of the mininginduced stress, fracture development, and so on. When the drawing process is performed, the loose top coal blocks flow out of the support opening (SO), and then they are transported by the rear scraper conveyor. LTCC was introduced from France to China in 1982; through almost 40 years' improvement of the theory and technology, it has been widely applied and become a representative achievement in thick seams mining $[1,2]$. LTCC has great applicability to seam thicknesses [3-8], seam dip angles [9-12], roof conditions [13, 14], gangue seam thicknesses [15-17], and so on. It has been successfully used in different complex geological conditions, with a relatively high recovery ratio [18-21]. Compared with slicing mining, LTCC saves plenty of labor and material resources, such as equipment conveyance and roadway excavation, which have great economic advantages. 


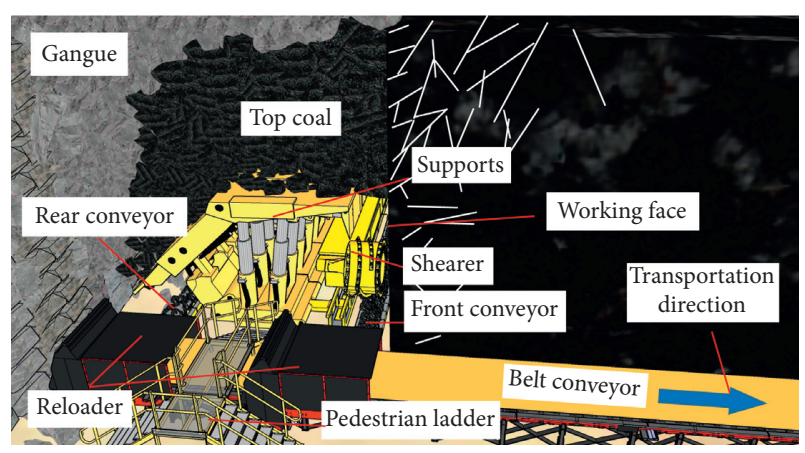

Figure 1: Schematic diagram of an LTCC panel.

Drawing mechanism [22-25] and fracture law [26-29] of top coal are core researches in LTCC. Effective fracture of top coal is the premise of smooth top coal drawing, and the recovery ratio is the comprehensive reflection of the broken degree of the top coal body. The optimization of top coal caving technology is an efficient approach to improve the recovery ratio in LTCC panels. To improve the recovery ratio under different conditions of LTCC panels, scholars mainly try to adjust the drawing rounds (one round, two rounds, or three rounds), drawing sequences (positive order or reverse order), and the number of SOs (single-opening or multiopening) along the layout direction and to change the drawing interval (one cutting and one drawing, two cuttings and one drawing, or three cuttings and one drawing) along the advance direction [3, 30, 31]. The crossed combination of the above factors can form different top coal caving technologies, which have a great effect on the drawing body shape, top coal boundary, and variation of recovery ratio. At present, the conventional single-opening sequential caving technology (SOSCT) is usually used in LTCC panels, which is easily mastered by workers and has a relatively high recovery ratio in thick coal seams. However, when SOSCT is applied in extrathick coal seams, the residual top coal between drawing bodies is large, leading to a low recovery ratio and poor drawing balance, which makes SOSCT no longer applicable. Contrarily, the multiopening sequential caving technology (MOSCT) can allow the large size top coal to flow out of SO, increasing the recovery ratio and advance velocity in the extrathick coal seams [18].

In summary, the multiopening caving technology (MOCT) is an inevitable choice to improve mining efficiency in extrathick coal seams. To further improve the recovery ratio and drawing balance in extrathick seams, the drawing sequence and drawing mechanism should be investigated using MOCT. This paper firstly puts forward a cluster-group naming method for the top coal caving technology, and then an independent cluster-group caving technology (ICGCT) is proposed. By the discrete element method $\mathrm{PFC}^{2 \mathrm{D}}$, the top coal drawing experiments are carried out under SOSCT, MOSCT, and ICGCT, respectively. Comparing the drawing mechanism of different caving technologies, the results verify the advantages of ICGCT, which lays a foundation for improving the recovery ratio in extrathick coal seams.

\section{Theoretical Analysis of MOCT}

To verify the applicability of MOCT in extrathick seams, researchers theoretically analyze the drawing body shape and the effect of MOCT on the dirt band.

2.1. Drawing Body Shape. In flat coal seams, according to the Bergmark-Roos model [32], the drawing body shape along the layout direction satisfies

$$
\rho=\frac{1}{2} g t^{2}\left(\cos \theta-\cos \theta_{G}\right),
$$

where $\rho$ is the distance between particles to the original point; $g$ is the gravity accelerometer; $t$ is the drawing time; $\theta$ is the angle of a particle; and $\theta_{G}$ is the maximum movement angle of top coal particles.

When $\theta_{G}=30^{\circ}$, the drawing body shape is shown in Figure 2. When $\theta=0^{\circ}$, the maximum drawing height $(H)$ can be obtained by

$$
H=\frac{1}{2} g t^{2}\left(1-\cos \theta_{G}\right) .
$$

The radius of the drawing body $(L)$ in each layer meets

$$
L=H \frac{\sin \theta\left(\cos \theta-\cos \theta_{G}\right)}{\left(1-\cos \theta_{G}\right)} .
$$

From equation (3), it is found that $L$ is maximum when $\theta=17^{\circ}$. Therefore, with rising $H, L$ gradually increases, revealing that the area of drawing top coal gradually extends.

Supposing that $\theta=\theta_{G}^{\prime}$, then $L$ is equal to $d$ at this moment. Equations (2) and (3) change into

$$
d=H \frac{\sin \theta_{G}^{\prime}\left(\cos \theta_{G}^{\prime}-\cos \theta_{G}\right)}{\left(1-\cos \theta_{G}\right)}=\frac{1}{2} g t^{2} \sin \theta_{G}^{\prime}\left(\cos \theta_{G}^{\prime}-\cos \theta_{G}\right),
$$

where $d$ is a half of the opening length and $\theta_{G}^{\prime}$ is a constant, which can be calculated by $\theta_{G}$ [33]. In Figure 2, $D_{1}$ is the opening length in SOSCT and $D_{2}$ is the length in MOCT.

In equation (4), with $H$ becoming larger, $d$ also needs to become larger; that is, the opening length needs a gradual increase in extrathick seams. In addition, when the opening length becomes larger, $t$ gradually increases. Therefore, with increasing opening length, a larger drawing area is obtained, revealing that MOCT is conducive to the drawing process in extrathick seams. As shown in Figure 2, when SOSCT is applied in extrathick seams, due to the restraint of the top coal boundary [34], the development of the drawing body is limited (the yellow drawing body in Figure 2), leading to more residual top coal staying in the goaf and decreasing the recovery ratio. However, under the same top coal boundary, when MOCT is used in the panel, the drawing body is more developed toward the goaf side, which makes the volume of residual top coal significantly decrease. Therefore, to realize the purpose of a larger touch between the drawing body and top coal boundary [2], MOCT is a more available technology in the extrathick seams. 


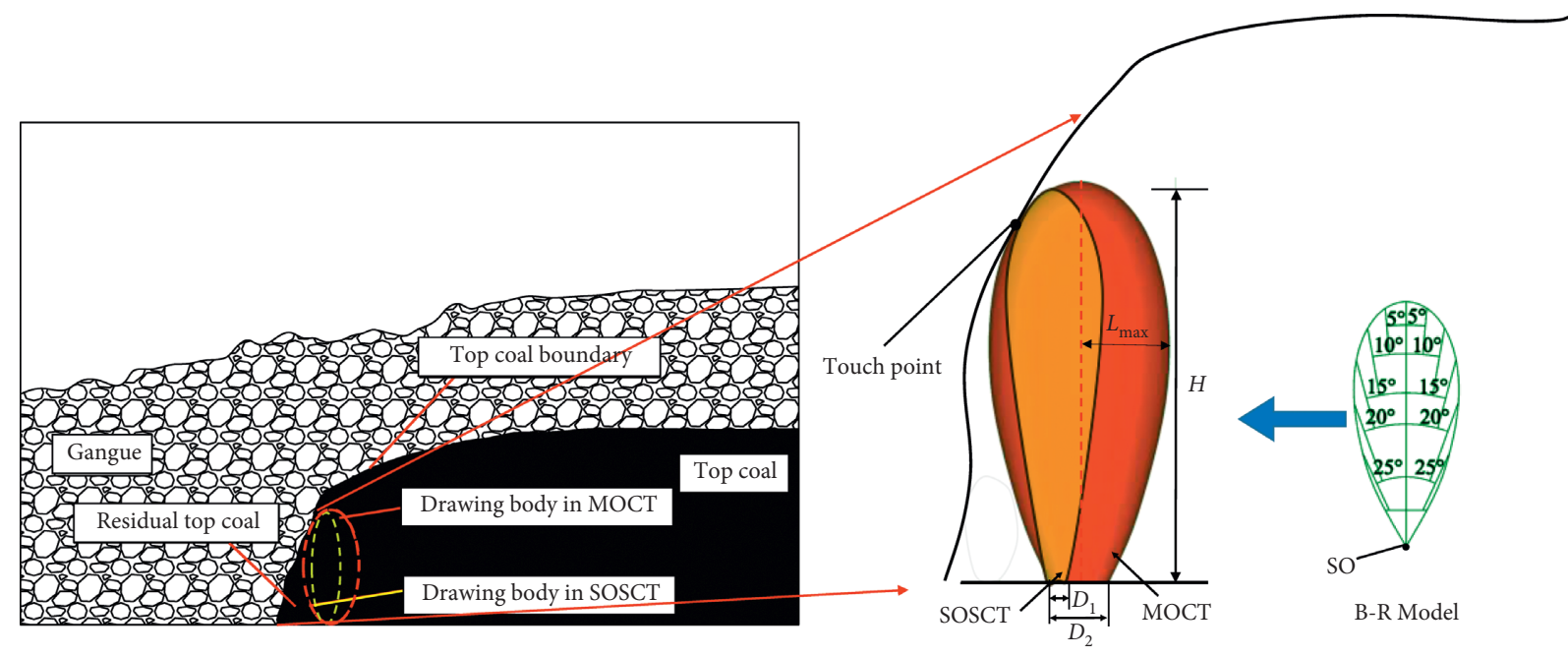

Figure 2: Comparison of different drawing bodies.

2.2. Effect of MOCT on the Dirt Band. In extrathick seams, the dirt band usually appears in the form of one or more layers. When the strength and thickness of the dirt band are relatively large, the top coal at the upper of the dirt band cannot flow toward SO, which causes coal loss and decreases the recovery ratio. As shown in Figure 3, due to the large area of drawing top coal by using MOCT, a large hanging area between the drawn top coal and dirt band will form, which is conducive to the break of the dirt band. Furthermore, with increasing number of SOs, the hanging area gradually rises.

To clearly illustrate the effect of the hanging area on the broken degree, the hanging area can be simplified as a long beam in the layout direction. Based on the mechanics of materials, when the two ends of the beam are fixed, the maximum deflection of a beam $\left(\omega_{\max }\right)$ can be calculated by

$$
\omega_{\max }=\frac{5 q l^{4}}{384 \mathrm{EI}},
$$

where $q$ is the uniformly distributed load; $E$ is the elasticity modulus; $I$ is the second moment of area. From equation (5), when other parameters are confirmed, with increasing $l$, $\omega_{\max }$ will greatly increase in a form of fourth power. In summary, MOCT can increase the drawing area, reduce the residual top coal, and also improve the probability of the dirt band breaking, leading to a higher recovery ratio in extrathick seams. However, with the variation of drawing sequence, the drawing mechanism is difference in MOCT. Therefore, the following sections propose a cluster-group caving technology and systematically investigate the mechanism of improving the recovery ratio.

\section{Cluster-Group Caving Technology}

3.1. Naming Method. When the drawing sequence and drawing number of SOs are different in MOCT, the name of caving technologies is usually different. To unify the naming method, the cluster-group naming method is proposed in Figure 4. Specifically, all supports are firstly divided into several clusters along the layout direction of the panel, then a cluster is divided into several groups, and a group consists of some supports. Therefore, the cluster-group naming method mainly includes the following factors: cluster code $(N)$, group code $(n)$, support code $(k)$, and independent identifying code $(\alpha, \alpha=0,1,2,3, \ldots)$, which is used to distinguish the number of the clusters or groups simultaneously drawing top coal.

As shown in Figure 4(a), the order of $N$ determines whether it is sequential to perform the drawing process along the layout direction. When $N$ gradually increases, it represents the positive drawing process between clusters; contrarily, it is the reverse drawing process. It is noted that when $n$ gradually decreases along the layout direction, it means the positive drawing process between groups. $k$ gradually increases along the layout direction. In Figure 4(b), a complete code on a support for illustrating the clustergroup naming method is $N\left(\alpha N_{1}\right)-n\left(\alpha n_{1}\right)-k\left(\alpha k_{1}\right)$. In the code, $N, n$, and $k$ define the position and number of the supports; $N_{1}$ is the maximum of clusters, $n_{1}$ is the maximum of groups in a cluster, and $k_{1}$ is the maximum of supports in a group. $\alpha$ is the first number located in the bracket. When $\alpha=0$, the drawing process is independent in different clusters and groups; while when $\alpha \neq 0$, the drawing process is dependent or relative in different clusters and groups. The number of clusters and groups are determined by the length of the panel and the seam thickness. The relationship between the total number of supports $(x)$ and the above parameters meets

$$
k_{1} \times n_{1} \times N_{1}=x .
$$

Code 6(2040)-1(0002)-35(0003) on the yellow support (Figure 4(b)) means that a total of 40 clusters and 240 supports are in the panel. Furthermore, a cluster includes 2 groups, and the group consists of 3 supports. This support is located in the sixth cluster and the first group, with a number of 35. In addition, $\alpha$ is equal to 2 in the code, which reveals that all supports of two clusters open SOs at the same time. Particularly, when the code is 1(0160)-1(0001)-1(0001), it is shown that a total of 160 supports are in the panel, a group is in a cluster, and a support is in a group. This position of this support is in the first cluster and the first group, with a 


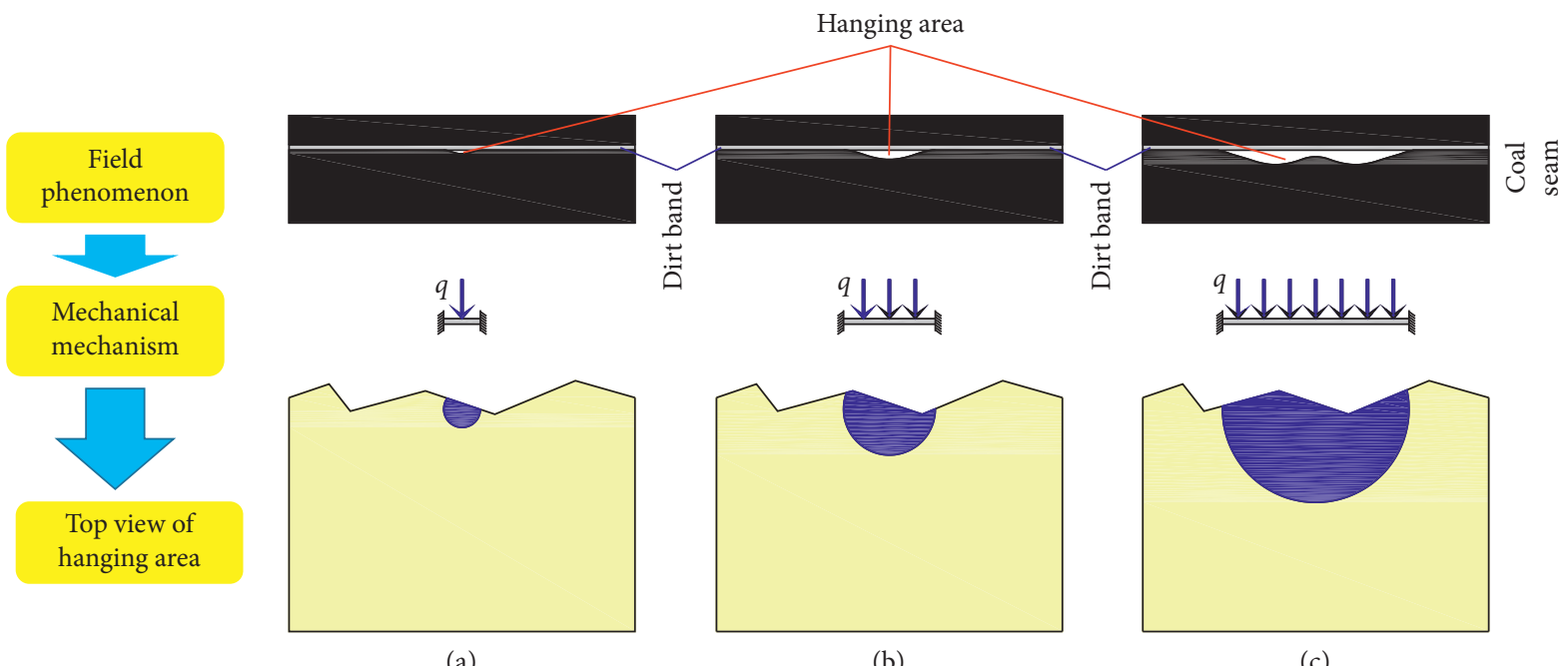

FIGURE 3: Hanging area under different conditions: (a) SOSCT; (b) MOCT with three SOs; (c) MOCT with six SOs.

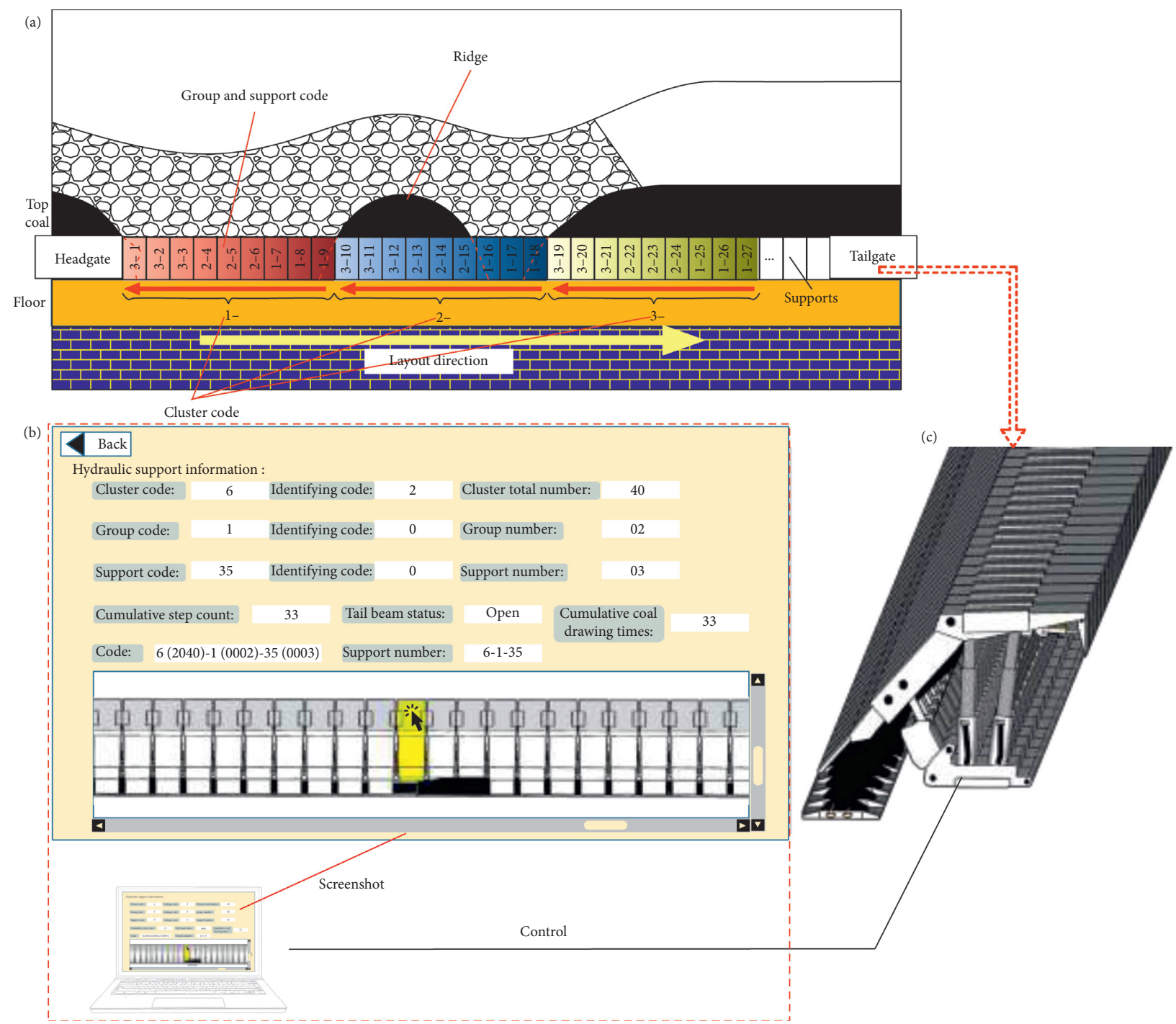

FIGURE 4: Cluster-group naming method: (a) support dividing into clusters and groups; (b) operation system; (c) controlled support. 
number of 1 . Due to $\alpha=0$, the drawing process of each support is independent. In short, this code represents the simplest SOSCT. Therefore, when all supports have been arranged by a cluster-group naming method, the drawing experiment can be carried out based on the principle of seeing the first gangue particle and then closing the SO.

3.2. Independent Cluster-Group Caving Technology. The cluster-group naming method includes and standardizes the names of previous top coal caving technologies. Combining with MOSCT and the dynamic subsection caving technology $[35,36]$, the independent cluster-group caving technology (ICGCT) is proposed based on the new naming method, where the drawing process of each cluster and group is independent. Taking $N_{1}=2, n_{1}=3$, and $k_{1}=3$ as an example, the code of a support can be written as 1(0002)-1(0003)$9(0003)$ in ICGCT. It is found that a total of 2 clusters, 6 groups, and 18 supports are in the panel, and the drawing process is performed according to the cluster and group number in turn. Under the same conditions, the code of the support can be recorded as 1(0018)-1(0001)-9(0001) in SOSCT that is 1(0002)-3(0003)-9(0003) in MOSCT. To verify the advantage of ICGCT, the variations of the recovery ratio, drawing body, top coal boundary, and the drawing balance need to be further investigated under different caving technologies.

\section{Numerical Simulation}

4.1. Model Establishment and Schemes Design. Figure 5 shows the initial model of drawing experiments by the discrete element method $\mathrm{PFC}^{2 \mathrm{D}}$. The model length is $45 \mathrm{~m}$, the thickness of simulated top coal (blue balls) is $10 \mathrm{~m}$, and the thickness of simulated gangue (green balls) is $6 \mathrm{~m}$. A total of 30 supports are arranged in the panel, and 18 supports carry out the drawing process in the middle part of the panel, referred as to the drawing area. To eliminate the effect of model boundary on drawing experiments, 6 supports are set as the panel end in the model, respectively. The left end (supports 1-6) is referred to as lower end, and the right end (supports 25-30) is written as the upper end. Furthermore, to simulate the uneven floor more accurately, this model uses the clump element consisting of 10 balls instead of the wall element to perform drawing experiments, which improve the accuracy of numerical results. The contact between ball and ball uses the linear contact model, and the mechanical parameters of top coal and gangue particles are shown in Table 1 .

To compare the drawing mechanism under different caving technologies, three experimental schemes (SOSCT, MOSCT, and ICGCT) are designed, and the detailed information about the arranged cluster and group is shown in Table 2. The symbol "[]" represents a cluster, and the "()" means a group in MOSCT and ICGCT. It can be known that 2 clusters and 6 groups are in MOSCT and ICGCT, and 3 supports are in a group, which will open SOs simultaneously. In the drawing process, Fish language is employed to control the opening and closing of SO. When the first gangue ball flows out of SO, it will be closed quickly.
4.2. Variation of the Recovery Ratio. When the drawing process is finished in three caving technologies, this research firstly calculates the value of the recovery ratio. The recovery ratio of the panel $\left(r_{p}\right)$ meets

$$
r_{p}=\frac{N_{d}}{N_{0}} \times 100 \%,
$$

where $N_{d}$ is the total number of drawn top coal particles and $N_{0}$ is the total number of top coal particles between SOs 5-26. The calculated results are shown in Figure 6. Compared with SOSCT, $r_{p}$ is larger in MOSCT and ICGCT, verifying that multiopening caving can improve the top coal recovery in extrathick seams. Furthermore, $r_{p}$ of ICGCT is the largest in the three technologies, at $93.5 \%$, which is higher than $r_{p}$ of MOSCT, revealing that change of the drawing sequence is beneficial to increase $r_{p}$ in ICGCT.

The recovery ratio of each support $\left(r_{s}\right)$ can be given by

$$
r_{s}=\frac{N_{d i}}{N_{o i}} \times 100 \%,
$$

where $N_{d i}$ is the total number of drawn top coal particles by SO $i$ and $N_{0 i}$ is the total number of top coal particles above SO $i$. Figure 7 illustrates the results under three caving technologies. It can be found that ICGCT (the blue line) mainly increases the top coal recovery in the middle part and upper end of the panel, which is caused by the drawing process with a reverse sequence in each cluster under ICGCT. The change of recovery ratio is an interaction result between the drawing body and the top coal boundary, whose shapes are introduced in detail in the following section.

4.3. Top Coal Boundary. The development of the top coal boundary under three technologies is recorded in Figure 8. In each technology, three drawing stages are selected as the research object. In SOSCT, the drawing process is from the lower end to the upper end in turn. It can be found that the change trend of the initial top coal boundary is relatively unsmooth in SOSCT. With continuing the drawing process, the residual top coal is less in the middle drawing stage; however, it significantly increases in the finishing drawing stage. In MOSCT, the evolution of top coal boundary is similar to that in SOSCT, and the difference is that the volume of the residual top coal is relatively small. In ICGCT, the drawing sequence is different from others; thus, the coal ridge appears in the middle drawing stage, which gradually reduces in following drawing processes. In summary, the residual top coal is less in the middle part and the upper end of the panel, while that is larger in the lower end. The reason is that the top coal of the lower end is the last part to be drawn, and the actual drawing height is less than the seam thickness, leading to a large coal loss.

4.4. Drawing Body Shape. The drawing body shape directly affects the top coal recovery in LTCC panels. As shown in Figure 9, it is drawing body shapes of different SOs under three caving technologies. The red dotted lines are the 


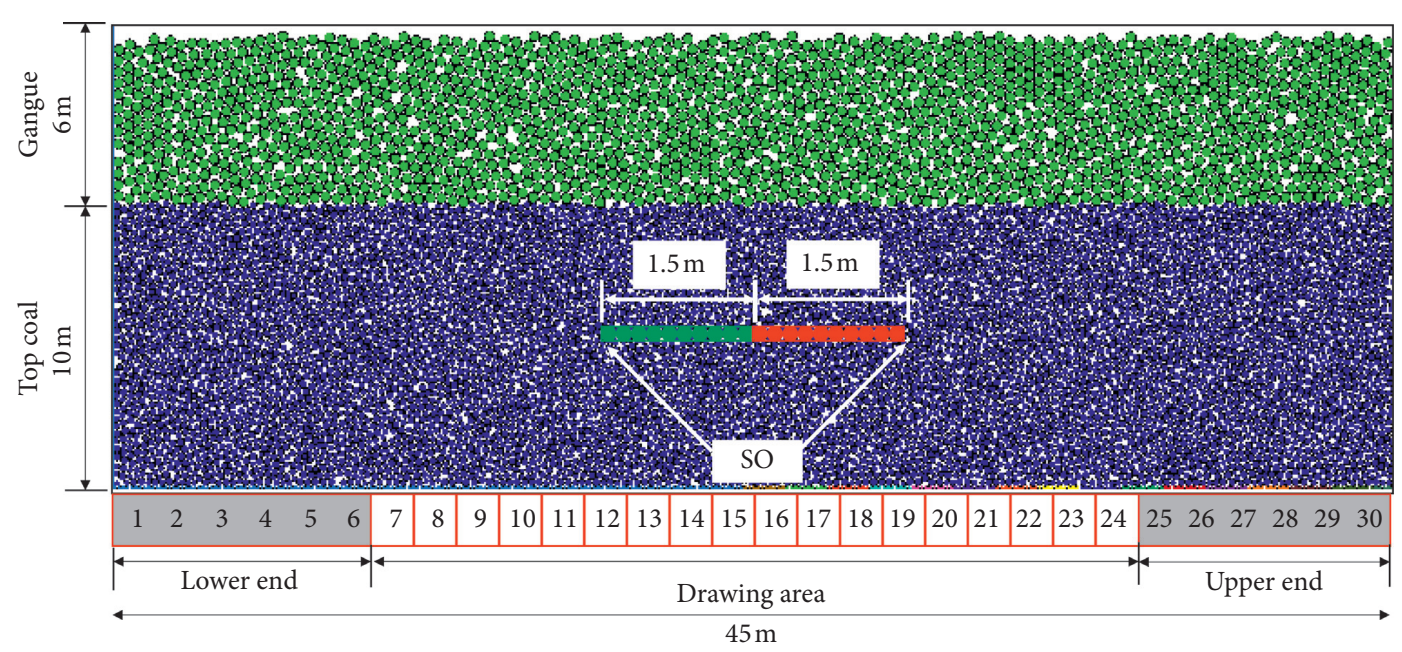

Figure 5: The initial $\mathrm{PFC}^{2 \mathrm{D}}$ model of drawing experiments.

TABle 1: Mechanical parameters of the top coal and gangue particles.

\begin{tabular}{lcccccc}
\hline Materials & Thickness & Radius & Density & Normal stiffness & Shear stiffness & Friction coefficient \\
\hline Unit & $\mathrm{m}$ & $\mathrm{mm}$ & $\mathrm{kg} / \mathrm{m}^{3}$ & $\mathrm{~N} / \mathrm{m}$ & $\mathrm{N} / \mathrm{m}$ & \\
Coal & 10 & $100-150$ & 1400 & $2 \times 10^{8}$ & $2 \times 10^{8}$ & 0.4 \\
Rock & 6 & 200 & 2400 & $4 \times 10^{8}$ & $4 \times 10^{8}$ & 0.4 \\
\hline
\end{tabular}

Table 2: The designed experimental schemes.

\begin{tabular}{lc}
\hline Caving technology & Drawing sequence \\
\hline SOSCT & $7-8-9-10-11-12-13-14-15-16-17-18-19-20-21-22-23-24$ \\
MOSCT & {$[(7-8-9)-(10-11-12)-(13-14-15)]-[(16-17-18)-(19-20-21)-(22-23-24)]$} \\
ICGCT & {$[(13-14-15)-(10-11-12)-(7-8-9)]-[(22-23-24)-(19-20-21)-(16-17-18)]$} \\
\hline
\end{tabular}

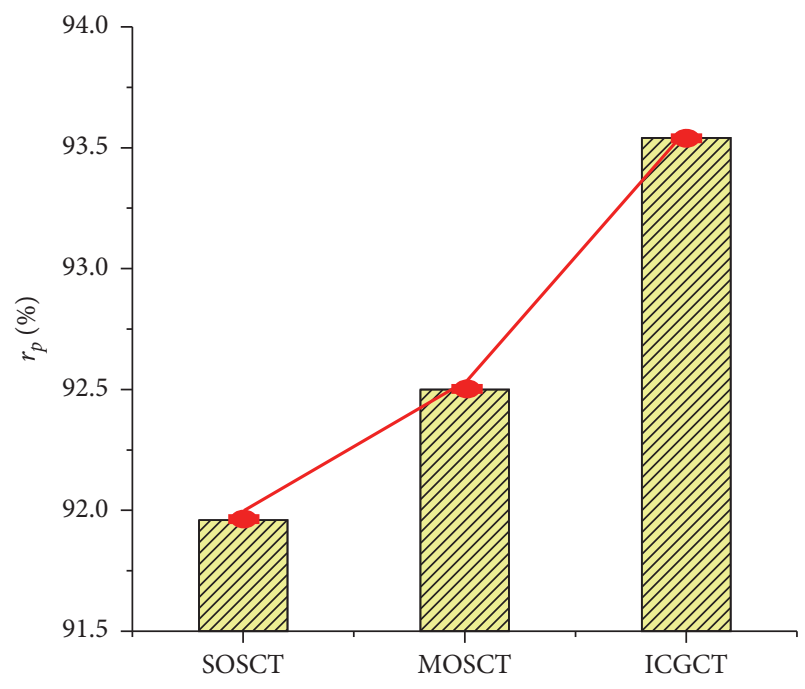

FIGURE 6: The variation of $r_{p}$ under three caving technologies.

boundary of the drawing area, and numbers in white boxes are the sequence of drawing bodies in different caving technologies.

In SOSCT, the initial drawing body (the black area in Figure 9(a)) is basically an ellipse without the effect of the top

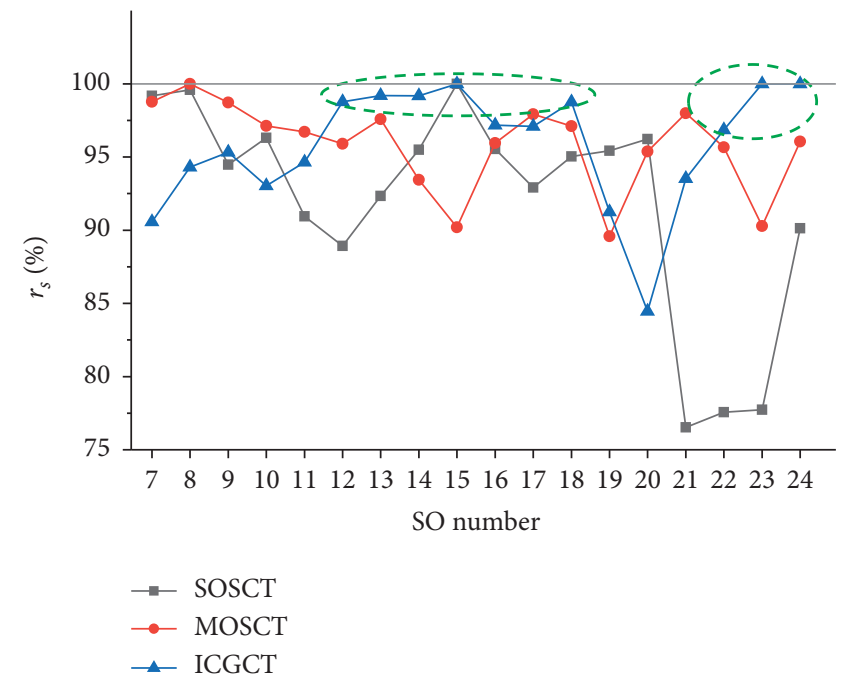

FIgURE 7: The change of $r_{s}$ under three caving technologies.

coal boundary. In the normal drawing stage (the drawing process at SOs 7-24), the drawing body shapes are nearly sickle in the initial model; however, the volume of the drawing bodies is not uniformly distributed in the panel. Furthermore, the residual top coal between two drawing 
(a)
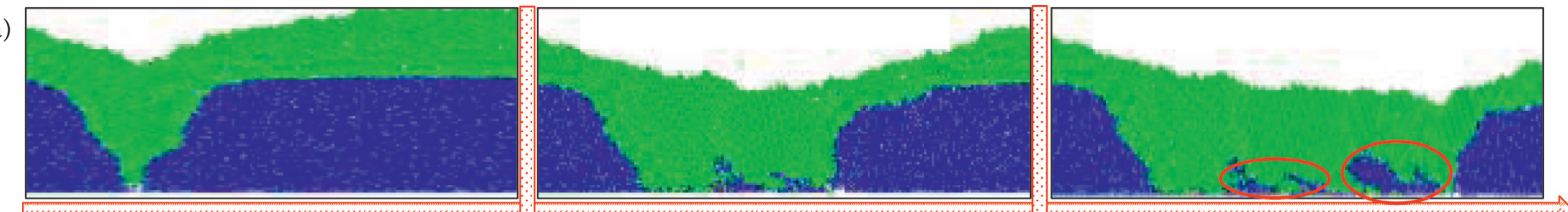

(b)
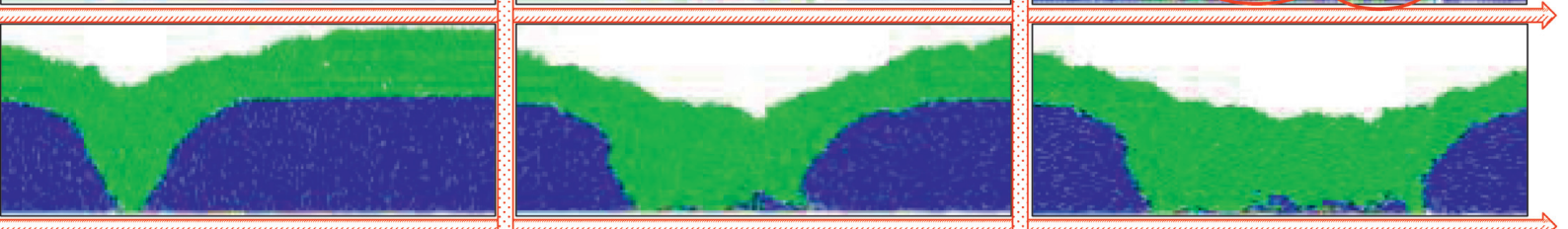

(c)
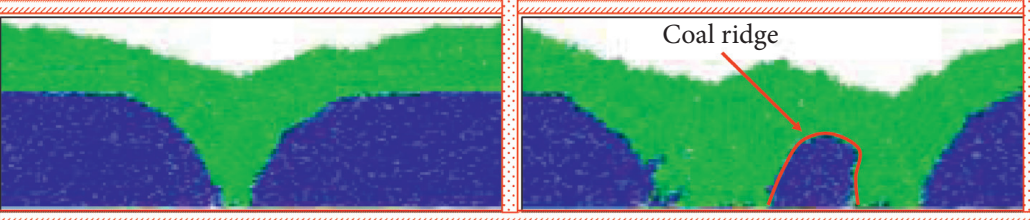

Middle drawing

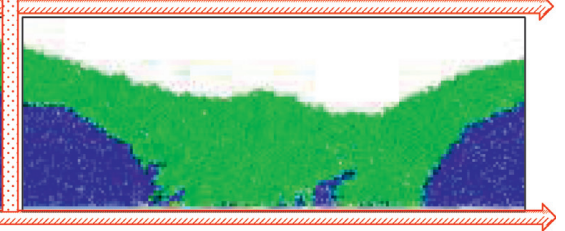

Finishing drawing

FIGURE 8: Top coal boundary under three caving technologies: (a) SOSCT; (b) MOSCT; (c) ICGCT.
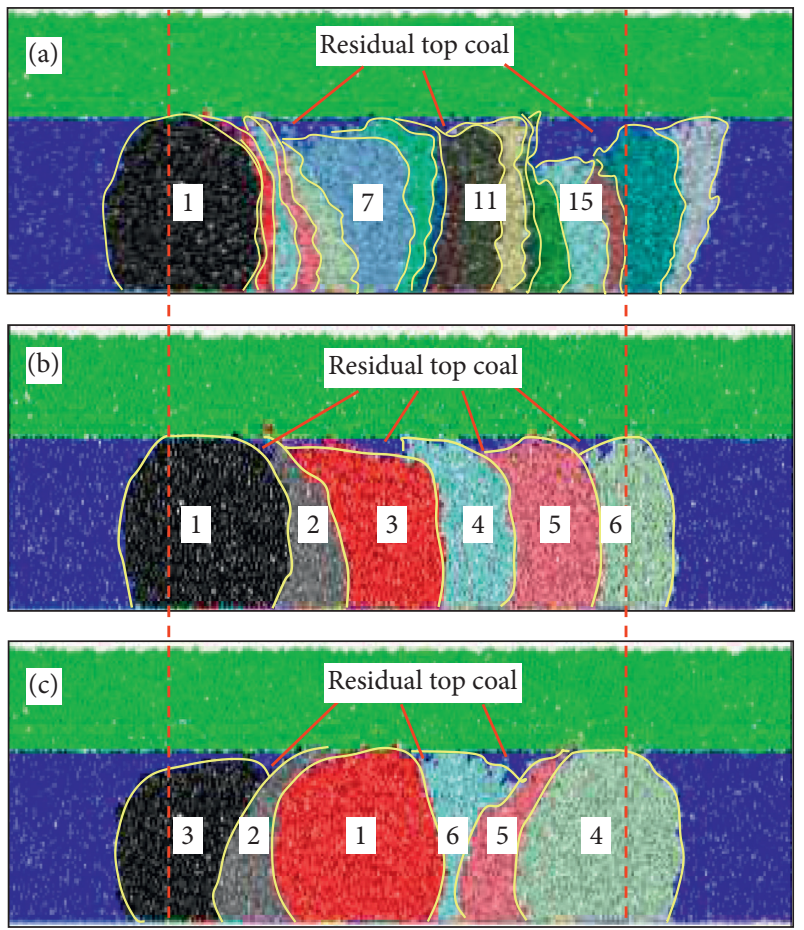

FIGURE 9: Drawing body shapes under (a) SOSCT, (b) MOSCT, and (c) ICGCT.

bodies is relatively large in the drawing area, leading to a smaller recovery ratio. In MOSCT, three supports are a group, which is the minimum unit to perform the drawing process. Similarly, the initial drawing body is an approximate ellipse, with a larger maximum width. Compared with the residual top coal in SOSCT, it greatly reduces in MOSCT. In ICGCT, two completely developed drawing bodies are in different clusters, respectively, which make the recovery ratio higher in the middle part and panel end, verifying the analysis of Chapter 4.2 .
4.5. Dispersion Degree of Top Drawn Coal. In LTCC panels, the volume of drawn top coal is different in each drawing process, thus workers are confused about when to close SO for decreasing the gangue mixed ratio. At present, workers mainly control SO by listening to the sound of gangue hitting the support tail beam and seeing the gangue flow out of SO; however, the accuracy depends on the worker's experience. When SO is closed earlier, part of the top coal will be left in the goaf, reducing the recovery ratio. On the contrary, if SO is closed late, a large amount of gangue will be mixed into the top coal, which will increase the later washing cost. Therefore, it is necessary to conduct further quantitative analysis on the top coal volume from different SOs.

To describe the dispersion degree of different drawn volumes, the dispersion coefficient $\left(K_{d}\right)$ is defined, which can be obtained by

$$
K_{d}=\frac{K_{i} m}{N_{d}},
$$

where $K_{i}$ is the drawn number of top coal particles in the $i$-th drawing process; $m$ is the total number of drawing processes; and $N_{d}$ is the total number of drawn top coal particles. From equation (9), $K_{d}$ means the ratio of the drawing number of each time and the average drawing number. When $K_{d}$ is larger than 1, it indicates that the drawing volume is large in this drawing process.

Figure 10 shows the variation of $K_{d}$ under three caving technologies. When $i=1, K_{d}$ is approximately equal to 4.5 in SOSCT, indicating that the drawing volume at the first drawing process is much larger than the average value. In the following drawing sequences, the value of $K_{d}$ fluctuates between 0 and 2.5. However, the changing trend is irregular, which is not conducive to the management of the panel. In MOSCT and ICGCT, both the value of $K_{d}$ varies between 0.5 and 1.7, with a small change range. Furthermore, $K_{d}$ changes more regularly and in a wavy shape in 


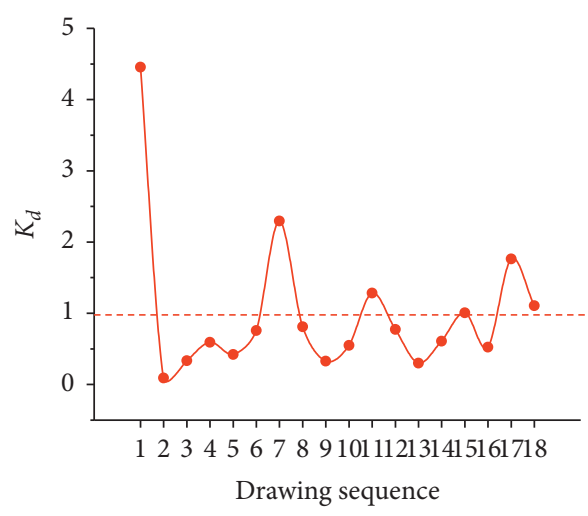

(a)

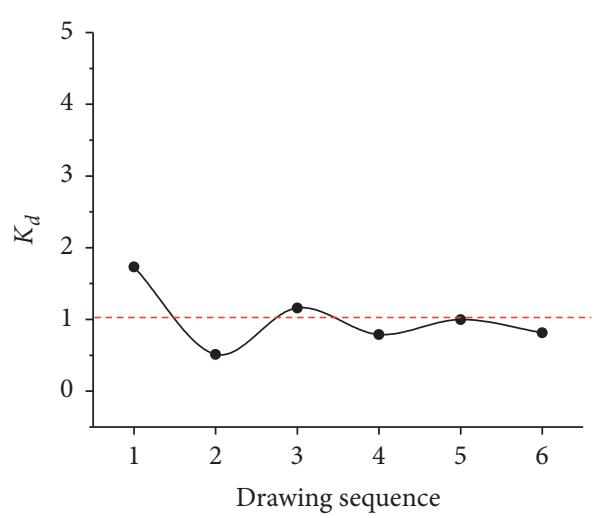

(b)

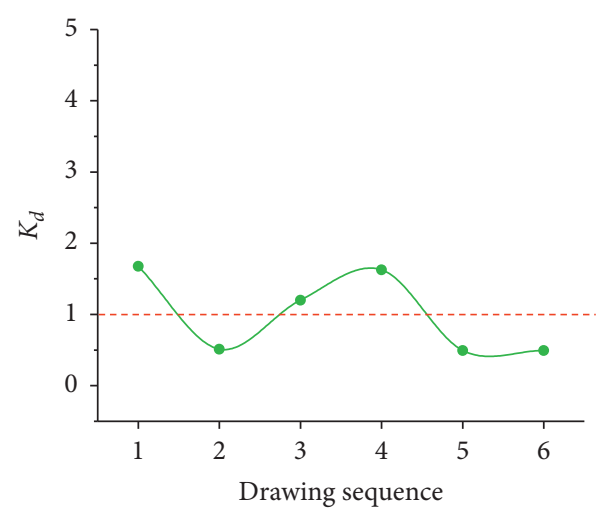

(c)

Figure 10: The variation of $K_{d}$ under (a) SOSCT, (b) MOSCT, and (c) ICGCT.

ICGCT, which is determined by its drawing sequence. Through the variation law of $K_{d}$ in the two caving technologies, it is proved again that MOCT is beneficial to improve the drawing balance in extrathick coal seams and to optimize the controlling of SO.

In summary, ICGCT not only improves the recovery ratio in LTCC panels with an extrathick coal seam but also optimizes the balance of drawing volumes, which lays a foundation for intelligent longwall top coal caving mining.

\section{Discussion}

In the above analysis, the drawing process is independent in different clusters; that is, $\alpha$ is equal to 0 . However, when the group with the same number starts drawing operation in different clusters, referred to as the dependent cluster-group caving technology (DCGCT), whose drawing efficiency is investigated by Figure 11.

In DCGCT, the drawing sequence is (13-14-15-22-2324)-(10-11-12-19-20-21)-(7-8-9-16-17-18). It can be seen that the recovery ratio of DCGCT is slightly higher than that of ICGCT. The main reason is that, in ICGCT, the drawing body is developed under the effect of top coal boundary in Group 1 of Cluster 2. However, the drawing body development of the same position is basically under the initial condition in DCGCT, leading to a higher recovery ratio in panel ends. Furthermore, compared with

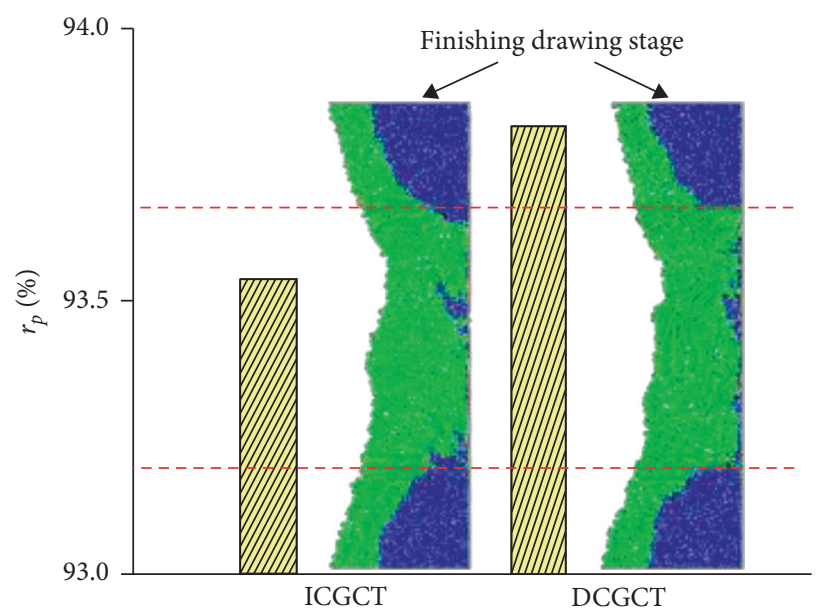

FIgURE 11: Comparison of drawing efficiency under ICGCT and DCGCT.

the top coal boundary in ICGCT, it has a larger development range at the two panel ends in DCGCT, indicating that the number of drawn top coal particles is relatively larger, which also verifies the correctness of the above analysis. In addition, the drawing volume is relatively large in one-time drawing process under DCGCT; therefore, a more powerful rear scraper conveyor needs to be arranged in the panel. 
In summary, researchers mainly investigate the drawing mechanism under different caving technologies, verifying the superiority of ICGCT. However, the effect of seam thickness, mining-caving ratio, the number of arranged clusters and groups, and other factors on the drawing mechanism still needs to be analyzed in the next study. In addition, this research mainly studies the drawing process along the layout direction of the panel, and the drawing law of ICGCT along the advance direction also needs further analysis.

\section{Conclusions}

Aimed at the problems of low recovery ratio and poor drawing balance in extrathick coal seams, firstly, this research theoretically analyzes the shape characteristics of the drawing body under MOCT, as well as its breaking effect on the dirt band in coal seams, verifying that MOCT is suitable for the LTCC panel with an extrathick seam. Then, a systematic cluster-group naming method is proposed, and ICGCT is also given. To verify the advantages of ICGCT, the variations of the recovery ratio, drawing body, top coal boundary, and drawing balance are compared with that under SOSCT and MOSCT. The main conclusions are as follows:

(1) Compared with SOSCT and MOSCT, ICGCT significantly improves the recovery ratio of the panel. By analyzing the recovery ratio of the same support under different caving technologies, the results show that ICGCT mainly increases the drawing volume of top coal in the middle and upper end of the panel.

(2) The shape of the top coal boundary reflects the drawing efficiency. Due to the effect of drawing sequence under ICGCT, the generation and disappearance process of coal ridge greatly decreases the residual top coal in the middle of the panel, improving the recovery ratio.

(3) The drawing body shape has a direct influence on the recovery ratio. In SOSCT and MOSCT, only the initial drawing body is fully developed, and the subsequent drawing bodies are mostly sickle shape under the restriction of the top coal boundary. However, multiple complete drawing bodies exist in ICGCT, and $K_{d}$ changes periodically in the range of $0.5-1.7$, which is conducive to the management of drawing processes in the extrathick seams.

(4) The drawing mechanism under ICGCT and DCGCT is discussed. The results show that the recovery ratio of DCGCT has a slight increase, which enlarges the maximum drawing range of top coal at both panel ends, shortening the drawing time of the panel. ICGCT and DCGCT provide a new approach for the intelligent LTCC with an extrathick seam.

\section{Data Availability}

The data used to support the findings of this study are included within the article.

\section{Conflicts of Interest}

The authors declare no conflicts of interest.

\section{Acknowledgments}

This work was supported by the Natural Science Foundation of China (Grant nos. 51974320 and 51934008).

\section{References}

[1] J. Wang, W. Wei, J. Zhang, and B. Mishra, "Laboratory and field validation of a LTCC recovery prediction model using relative size of the top coal blocks," Bulletin of Engineering Geology and the Environment, vol. 80, no. 2, pp. 1389-1401, 2021.

[2] Z. Y. Song, H. Konietzky, and M. Herbst, "Drawing mechanism of fractured top coal in longwall top coal caving," International Journal of Rock Mechanics and Mining Sciences, vol. 130, Article ID 104329, 2020.

[3] Q. L. Zhang, R. F. Yuan, S. Wang, Z. Wang, and L. Li, "Optimizing simulation and analysis of automated top-coal drawing technique in extra-thick coal seams," Energies, vol. 13, no. 1, p. 232, 2020.

[4] G. Y. Si, S. Jamnikar, J. Lazar et al., "Monitoring and modelling of gas dynamics in multilevel longwall top coal caving of ultra-thick coal seams, part I: borehole measurements and a conceptual model for gas emission zones," International Journal of Coal Geology, vol. 144-145, pp. 98-110, 2015.

[5] H. Yan, J. X. Zhang, R. M. Feng, W. Wang, Y. Lan, and Z. Xu, "Surrounding rock failure analysis of retreating roadways and the control technique for extra-thick coal seams under fullymechanized top caving and intensive mining conditions: a case study," Tunnelling and Underground Space Technology, vol. 97, Article ID 103241, 2020.

[6] J. L. Shi, S. H. Yan, Z. H. Xu, J. Xue, Z. Kaikai, and J. Zheng, "Analysis of the progressively enhanced mine pressure in the fully mechanized top coal caving work face of a $20 \mathrm{~m}$ ultrathick coal seam," Shock and Vibration, vol. 2021, Article ID 6678207, 11 pages, 2021.

[7] B. Yu, J. Zhao, and H. Xiao, "Case study on overburden fracturing during longwall top coal caving using microseismic monitoring," Rock Mechanics and Rock Engineering, vol. 50, pp. 507-511, 2017.

[8] Y. Z. Zhou, D. Zhang, G. Fan, S. Zhang, and S. Zhang, "Feasibility study on fully mechanized large mining height long wall top-coal caving mining in ultra-thick (20-30 m), parting-rich coal seams: a case study of the Laosangou mining field in China," Energy Sources Part A-Recovery Utilization and Environmental Effects, 2020.

[9] S. L. Yang, W. J. Wei, and J. W. Zhang, “Top coal movement law of dynamic group caving method in LTCC with an inclined seam," Mining Metallurgy \& Exploration, vol. 37, pp. 1545-1555, 2020.

[10] S. L Yang, J. W. Zhang, Y. Chen, and Z. Song, "Effect of upward angle on the drawing mechanism in longwall top-coal caving mining," International Journal of Rock Mechanics and Mining Sciences, vol. 85, pp. 92-101, 2016.

[11] J. C. Wang, S. L. Yang, and L. H. Li, “Toppling-slumping failure mode in horizontal sublevel top-coal caving face in steeply-inclined seam," Journal of China University of Mining and Technology, vol. 47, pp. 1175-1184, 2018.

[12] J. W. Zhang, J. C. Wang, W. J. Wei, Y. Chen, and Z. Y. Song, "Experimental and numerical investigation on coal drawing 
from thick steep seam with longwall top coal caving mining," Arabian Journal of Geosciences, vol. 11, no. 5, p. 96, 2018.

[13] Q. S. Bai, S. H. Tu, F. T. Wang, and C. Zhang, "Field and numerical investigations of gateroad system failure induced by hard roofs in a longwall top coal caving face," International Journal of Coal Geology, vol. 173, pp. 176-199, 2017.

[14] X. F. Wang, Y. Wang, D. S. Zhang et al., "Characteristics of strata behavior during thick seam mining by fully-mechanized top coal caving in a loess-covered gullied region," Minerals, vol. 7, no. 4, p. 63, 2017.

[15] Q. S. Bai, S. H. Tu, and F. Wang, "Characterizing the top coal cavability with hard stone band(s): insights from laboratory physical modeling," Rock Mechanics and Rock Engineering, vol. 52, no. 5, pp. 1505-1521, 2019.

[16] J. C. Wang, S. L. Yang, J. W. Zhang, and Z. Song, "3-D movement law of top-coal in near horizontal coal seam with multi-gangue under caving mining technique," Journal of China Coal Society, vol. 40, pp. 979-987, 2015.

[17] Z. P. Wu, J. H. Wang, Z. J. Wan et al., "A case study of cyclic top coal weakening process based on highly tough coal seam with partings," Shock and Vibration, vol. 2021, Article ID 8862044, 17 pages, 2021.

[18] J. C Wang, W. J. Wei, and J. W. Zhang, "Effect of the size distribution of granular top coal on the drawing mechanism in LTCC," Granular Matter, vol. 21, no. 3, p. 70, 2019.

[19] J. C Wang, W. J. Wei, J. W. Zhang, B. Mishra, and A. Li, "Numerical investigation on the caving mechanism with different standard deviations of top coal block size in LTCC," International Journal of Mining Science and Technology, vol. 30, no. 5, pp. 583-591, 2020.

[20] N. E. Yasitli and B. Unver, "3D numerical modeling of longwall mining with top-coal caving," International Journal of Rock Mechanics and Mining Sciences, vol. 42, no. 2, pp. 219-235, 2005.

[21] B. Unver and N. E. Yasitli, "Modelling of strata movement with a special reference to caving mechanism in thick seam coal mining," International Journal of Coal Geology, vol. 66, no. 4, pp. 227-252, 2006.

[22] Z. Y. Song and H. Konietzky, "A particle-based numerical investigation on longwall top coal caving mining," Arab Journal of Geoscience, vol. 12, p. 556, 2019.

[23] J. C. Wang, W. J. Wei, and J. W. Zhang, "Theoretical description of drawing body shape in an inclined seam with longwall top coal caving mining," International Journal of Coal Science and Technology, vol. 7, no. 1, pp. 182-195, 2020.

[24] G. Jeromel, M. Medved, and J. Likar, "An analysis of the geomechanical processes in coal mining using the Velenje mining method," Acta Geotechnica Slovenica, vol. 7, no. 1, pp. 31-45, 2010.

[25] R. Kumar, A. K. Singh, A. K. Mishra, and R. Singh, "Underground mining of thick coal seams," International Journal of Mining Science and Technology, vol. 25, no. 6, pp. 885-896, 2015.

[26] Z. H. Wang, J. C. Wang, and K. Wang, "A model for top-coal cavability assessment and its application in longwall top-coal caving," Chinese Journal of Rock Mechanics and Engineering, vol. 38, no. 1, pp. 49-62, 2019.

[27] J. C. Wang, F. Liu, and Z. H. Wang, "Experimental investigation on the movement mechanism of top coal in steeply inclined ultra-thick coal seams," Acta Mechanica Sinica, vol. 37, 2021.

[28] S. J. Miao, S. R. Wang, Y. Li et al., "Numerical research on top coal movement, failure mechanism and supports' stresses characters of fully mechanized top-coal caving in steep thick seam," in Proceedings of the 7th International Symposium on Safety Science and Technology (ISSST), vol. 8, pp. 1627-1631, Beijing, China, October 2010.

[29] V. Klishin, S. Nikitenko, and G. Opruk, "Longwall top coal caving (LTCC) mining technologies with roof softening by hydraulic fracturing method," IOP Conference Series: Materials Science and Engineering, vol. 354, Article ID 012015, 2018.

[30] L. H. Sun, H. G. Ji, Z. Y. Cai, B. Zhang, and B. Yang, "Top-coal caving process and movement characters of fully mechanized caving face in steeply dipping thick seam," Journal of Mining \& Safety Engineering, vol. 33, no. 2, pp. 208-213, 2016.

[31] Q. L. Zhang, J. C. Yue, C. Liu, C. Feng, and H. Li, "Study of automated top-coal caving in extra-thick coal seams using the continuum-discontinuum element method," International Journal of Rock Mechanics and Mining Sciences, vol. 122, Article ID 104033, 2019.

[32] F. Melo, F. Vivanco, and C. Fuentes, "On draw body shapes: from Bergmark-Roos to kinematic models," International Journal of Rock Mechanics and Mining Sciences, vol. 44, no. 1, pp. 77-86, 2007.

[33] M. E. Kuchta, "A revised form of the Bergmark-Roos equation for describing the gravity flow of broken rock," Mineral Resources Engineering, vol. 11, no. 4, pp. 349-360, 2002.

[34] W. J. Wei, Z. Y. Song, and J. W. Zhang, “Theoretical equation of initial top coal boundary in longwall top-coal caving mining," International Journal of Mining and Mineral Engineering, vol. 9, no. 2, pp. 157-176, 2018.

[35] J. C. Wang, W. J. Wei, J. W. Zhang et al., "Stability analysis of support around the longwall top-coal caving mining in steeply thick coal seam," Journal of China Coal Society, vol. 44, pp. 2783-2791, 2017.

[36] J. C. Wang, S. L. Yang, W. J. Wei, J. Zhang, and Z. Song, "Drawing mechanisms for top coal in longwall top coal caving (LTCC): a review of two decades of literature," International Journal of Coal Science \& Technology, 2021. 